\title{
Salegentibacter catena sp. nov., isolated from sediment of the South China Sea, and emended description of the genus Salegentibacter
}

\author{
Jiao-Yan Ying, ${ }^{1,2}$ Zhi-Pei Liu, ${ }^{1}$ Bao-Jun Wang, ${ }^{1}$ Xin Dai, ${ }^{1}$ Su-Sheng Yang ${ }^{2}$ \\ and Shuang-Jiang Liu ${ }^{1}$ \\ ${ }^{1}$ State Key Laboratory of Microbial Resources, Institute of Microbiology, Chinese Academy of \\ Sciences, Beijing 100080, P. R. China \\ ${ }^{2}$ College of Biological Sciences, China Agricultural University, Beijing 100094, P. R. China
}

Correspondence

Shuang-Jiang Liu

liusj@sun.im.ac.cn

\begin{abstract}
A novel marine bacterial strain, $\mathrm{HY}^{\top}{ }^{\top}$, was isolated from sediment of the South China Sea. The strain was aerobic and heterotrophic and formed saffron yellow-pigmented colonies on marine agar 2216. Cells were non-motile, Gram-negative rods, frequently occurring in chains. BLASTN searches revealed that the $16 \mathrm{~S}$ rRNA gene sequence of strain $\mathrm{HY}^{\top}$ showed high similarity with those of members of the genera Gillisia (91.7-93.8\%) and Salegentibacter (92.6-93.5\%). Phylogenetic analysis based on 16S rRNA gene sequences showed that the strain clustered with members of both Salegentibacter and Gillisia and phylogenetic trees constructed using three different methods (neighbour-joining, maximum-parsimony and minimum-evolution) indicated that strain $\mathrm{HY}_{1}^{\top}$ clustered more frequently with members of the genus Salegentibacter. The DNA G $+\mathrm{C}$ content of strain $\mathrm{HY} 1^{\top}$ was 44.4 mol\% and its major cellular fatty acids ( $\geqslant 5 \%$ of the total fatty acids) were iso-15 : 1 (5.0\%), iso-15: 0 (6.8\%), anteiso-15: 0 (6.4\%), $15: 0(10.4 \%)$, iso-16: 0 (13.5\%), summed feature 3 (comprising iso-15: 0 2-OH and/or $16: 1 \omega 7 c ; 6.3 \%$ ), iso- $17: 03-\mathrm{OH}(5.2 \%)$ and $17: 02-\mathrm{OH}(5.0 \%)$. Cells contained menaquinone 6 . Based on the phylogenetic and phenotypic analyses, strain $\mathrm{HY} 1^{\top}$ should be classified as representing a novel species within the genus Salegentibacter, for which the name Salegentibacter catena sp. nov. is proposed. The type strain is $\mathrm{HY}^{\top}{ }^{\top}$ (=CGMCC $1.6101^{\top}=\mathrm{JCM} 14015^{\top}$ ). Based on this study and on previously described Salegentibacter species, an emended description of the genus Salegentibacter is given.
\end{abstract}

The genus Salegentibacter was created by McCammon \& Bowman (2000) to accommodate strictly aerobic, nonmotile, yellow-pigmented and moderately halophilic (optimal growth with about $5 \% \mathrm{NaCl}$ ) bacteria. The type species Salegentibacter salegens was isolated from a hypersaline Antarctic lake (Dobson et al., 1993). Other members of this genus are as follows: Salegentibacter holothuriorum, isolated from the edible holothurian Apostichopus japonicus (Nedashkovskaya et al., 2004), Salegentibacter mishustinae from the sea urchin Strongylocentrotus intermedius (Nedashkovskaya et al., 2005), Salegentibacter agarivorans associated with sponge (Nedashkovskaya et al., 2006) and Salegentibacter flavus from sea sediment (Ivanova et al., 2006). Some of the recently described species showed characteristics that are not compatible with the original description of the genus Salegentibacter, e.g. S. agarivorans is

The GenBank/EMBL/DDBJ accession number for the 16S rRNA gene sequence of strain $\mathrm{HY}^{\top}{ }^{\top}$ is DQ640642.

Maximum-parsimony and minimum-evolution phylogenetic trees based on 16S rRNA gene sequences and electron micrographs of cells of strain $\mathrm{HY}^{\top}{ }^{\top}$ are available as supplementary material in IJSEM Online. motile by gliding (Nedashkovskaya et al., 2006) and most Salegentibacter species grow optimally with $\mathrm{NaCl}$ concentrations lower than 5\%. Besides Salegentibacter, many members of the family Flavobacteriaceae are found in various marine habitats, e.g. the genera Formosa (Ivanova et al., 2004), Gillisia (Van Trappen et al., 2004), Subsaximicrobium, Subsaxibacter and Lacinutrix (Bowman \& Nichols, 2005). The abundance of marine Flavobacteriaceae suggests that members of the family potentially play important roles in marine ecosystems and in biogeochemical cycles in interaction with other marine organisms (Bowman \& McCuaig, 2003).

During a study of microbial diversity of marine sediments in the South China Sea, a novel heterotrophic, aerobic, saffron yellow-pigmented, non-gliding, Gram-negative bacterial strain $\left(\mathrm{HY}^{\mathrm{T}}\right)$ was isolated. Here we describe the taxonomic investigation of the new isolate following the minimal standards for describing new taxa of the family Flavobacteriaceae (Bernardet et al., 2002).

Strain $\mathrm{HY} 1^{\mathrm{T}}$ was isolated from sediment of Xijiang oilfield in the South China Sea $\left(114^{\circ} \mathrm{E} 21^{\circ} \mathrm{N}\right)$, from a depth of about 


Gillisia limnaea
Gillisia mitskevichiae
Gillisia hiemivivida
Gillisia sandarakina
Gillisia illustrilutea
Strain HY1
Salegentibacter holothuriorum
Salegentibacter mishustinae
Salegentibacter agarivorans
Salegentibacter salegens
Salegentibacter flavus

Gillisia limnaea Gillisia mitskevichiae Gillisia illustrilutea Strain HY ${ }^{\mathrm{T}}$ Salegentibacter mishustinae Salegentibacter salegens Salegentibacter flavus
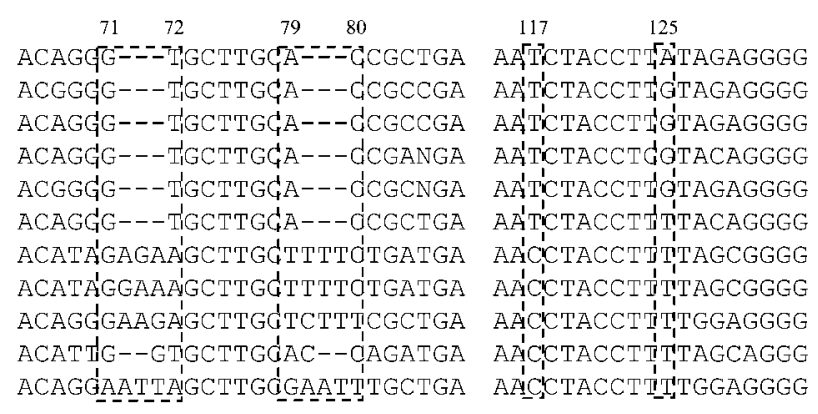

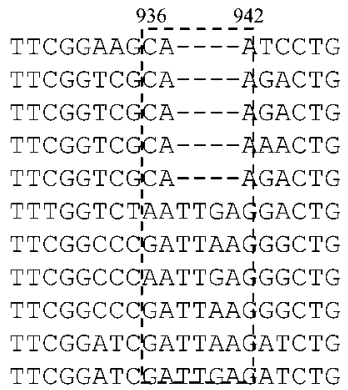

Fig. 1. Alignment of the $16 \mathrm{~S}$ rRNA gene sequences of members of the genera Gillisia and Salegentibacter and of strain $\mathrm{HY}_{1}{ }^{\top}$. Nucleotides are numbered according to the $16 \mathrm{~S}$ rRNA gene sequence of strain $\mathrm{HY}_{1}{ }^{\top}$ (DQ640642). GenBank accession numbers are as indicated in the phylogenetic tree (Fig. 2).

$100 \mathrm{~m}$. For isolation, serially diluted sediment samples were spread on low-organic marine (LOM) agar plates [containing $\left(\mathrm{g} \mathrm{l}^{-1}\right)$ : 0.5 peptone, 0.1 yeast extract and 15 agar, with the same salts composition and concentrations as Bacto marine broth 2216 (Difco)]. Colonies were picked and repeatedly restreaked on fresh LOM agar plates, until purity was confirmed. The isolates were subsequently tested for growth on plain marine agar 2216 at $30^{\circ} \mathrm{C}$, and cultivation and routine maintenance were subsequently carried out in plain marine broth 2216 .

The universal primers 27F and 1492R were used to amplify the 16S rRNA gene (Lane, 1991). The PCR product was ligated to T-vector and sequenced. BLASTN searches revealed that the $16 \mathrm{~S}$ rRNA gene sequence of strain $\mathrm{HY}^{\mathrm{T}}(1487 \mathrm{bp})$ showed high similarity with those of members of the genera Gillisia (91.7-93.8\%) and Salegentibacter (92.6-93.5\%). Alignments of the 16S rRNA gene sequences revealed that strain $\mathrm{HY}_{1}^{\mathrm{T}}$ shared characteristic nucleotide(s) at positions 71 and 72,79 and 80 and 117 with members of the genus Gillisia [numbering according to the $16 \mathrm{~S}$ rRNA gene sequence of strain $\mathrm{HY}^{\mathrm{T}}$ (DQ640642)] and characteristic nucleotide(s) at positions 125 and 936-942 with members of the genus Salegentibacter (Fig. 1). When phylogenetic trees were constructed using three different algorithms (neighbour-joining, maximum-parsimony and minimum-evolution) with MEGA version 3.1 (Kumar et al., 2004), strain $\mathrm{HY} 1^{\mathrm{T}}$ clustered more frequently with Salegentibacter species than with Gillisia species, although bootstrap values were low. The neighbour-joining tree is shown in Fig. 2, while the maximum-parsimony and minimum-evolution trees are available as Supplementary Fig. S1 in IJSEM Online.

The $\mathrm{G}+\mathrm{C}$ content of the DNA was analysed using the thermal denaturation method (Mandel \& Marmur, 1968; Seidler \& Mandel, 1971), with DNA from Escherichia coli K12 as a control. The DNA G $+\mathrm{C}$ content of strain $\mathrm{HY}^{\mathrm{T}}{ }^{\mathrm{T}}$ was $44.4 \mathrm{~mol} \%$. Biomass for the analysis of isoprenoid quinones was grown in marine broth 2216 and quinones were determined according to Collins (1985) and $\mathrm{Wu}$ et al. (1989). The isoprenoid quinone of strain $\mathrm{HY}^{\mathrm{T}}$ was menaquinone-6.

The whole-cell fatty acid composition of strain $\mathrm{HY}^{\mathrm{T}}$ was determined using the Sherlock Microbial Identification System, following the manufacturer's instructions. The fatty acid composition is given in the species description. Overall, it was similar to those of other Salegentibacter species, with the exception of Salegentibacter holothuriorum, which contains a lower amount of anteiso-15:0.

Physiological and biochemical characteristics of strain $\mathrm{HY}^{\mathrm{T}}$ were determined according to the methods described by Cho \& Giovannoni (2003) and Bernardet et al. (2002) and by using API ZYM kits (bioMérieux), according to the manufacturer's instructions. Susceptibility to antibiotics was determined using filter-paper discs containing various antibiotics on cultures incubated at $30^{\circ} \mathrm{C}$ on marine agar 2216 for 2 days. Cells often occurred in chains and some

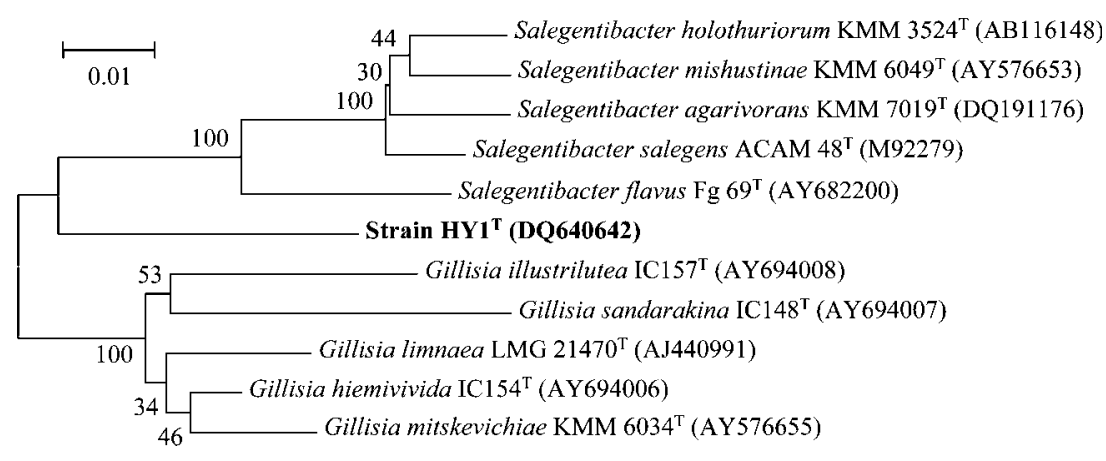

Fig. 2. Neighbour-joining tree based on the 16S rRNA gene sequences of strain $\mathrm{HY}^{\top}{ }^{\top}$ and Salegentibacter and Gillisia species. Bootstrap values (expressed as percentages of 1000 replications) $\geqslant 30 \%$ are shown at branching points. Bar, 0.01 substitutions per nucleotide position. 
cells of strain $\mathrm{HY}^{\mathrm{T}}$ possessed appendages (Supplementary Fig. S2 in IJSEM Online) in older cultures. Other morphological, physiological and biochemical properties of strain $\mathrm{HY}^{\mathrm{T}}$ are given in the species description. Characteristics that differentiate strain $\mathrm{HY}^{\mathrm{T}}$ from recognized Salegentibacter species are given in Table 1.

Combining the phylogenetic and phenotypic properties, it was concluded that strain $\mathrm{HY}^{\mathrm{T}}$ represents a novel species within the genus Salegentibacter, and the name Salegentibacter catena sp. nov. is proposed. As some properties of strain $\mathrm{HY}^{\mathrm{T}}$ and of previously described Salegentibacter species are not compatible with the original description of the genus Salegentibacter (McCammon \& Bowman, 2000), an emended description of the genus is also given.

\section{Emended description of the genus Salegentibacter McCammon and Bowman 2000}

Cells are Gram-negative rods, occurring as single cells, pairs or chains. Non-motile or motile by gliding. Do not form spores or other resting stages. Colonies are yellowpigmented. Flexirubin-type pigments are absent. Possess a strictly aerobic, chemo-organotrophic metabolism. Catalase-positive and positive for alkaline phosphatase

Table 1. Differential characteristics of Salegentibacter species

Taxa: 1, strain $\mathrm{HY}^{\mathrm{T}}$; 2, Salegentibacter flavus (data from Ivanova et al., 2006); 3, Salegentibacter salegens (Dobson et al., 1993; McCammon \& Bowman, 2000); 4, Salegentibacter holothuriorum (Nedashkovskaya et al., 2004); 5, Salegentibacter mishustinae (Nedashkovskaya et al., 2005); 6, Salegentibacter agarivorans (Nedashkovskaya et al., 2006). Data given are for the type strains. All are positive for catalase and alkaline phosphatase and hydrolysis of gelatin. +, Positive; -, negative; ND, not determined.

\begin{tabular}{|lcccccc|}
\hline Characteristic & $\mathbf{1}$ & $\mathbf{2}$ & $\mathbf{3}$ & $\mathbf{4}$ & $\mathbf{5}$ & $\mathbf{6}$ \\
\hline Gliding motility & - & - & - & - & - & + \\
Appendages & + & - & - & - & - & - \\
Oxidase & - & + & + & + & + & + \\
$\beta$-Galactosidase & - & $\mathrm{ND}$ & + & + & + & + \\
Nitrate reduction & - & - & + & - & - & + \\
$\mathrm{H}_{2}$ S production & + & - & + & + & + & + \\
Hydrolysis of: & & & & & & \\
$\quad$ Agar & - & - & - & - & - & + \\
$\quad$ Casein & + & - & - & - & + & - \\
$\quad$ Urea & - & + & - & - & - & - \\
Utilization of: & & & & & & \\
$\quad$ Mannose & - & $\mathrm{ND}$ & - & + & + & + \\
$\quad$ Lactose & - & - & + & + & + & $\mathrm{ND}$ \\
Production of acid from: & & & & & & \\
$\quad$ Arabinose & - & - & + & - & - & + \\
$\quad$ Maltose & - & $\mathrm{ND}$ & + & + & + & + \\
DNA G+C content (mol\%) & 44.4 & 40.4 & 41 & 36.8 & 37.5 & 39.2 \\
& & & & & & \\
& & & & & &
\end{tabular}

(not determined for Salegentibacter flavus). Grow in $0-20 \% \mathrm{NaCl}$ (all grow in 1-8\% $\mathrm{NaCl}$ ) and $\mathrm{NaCl}$ is required by most strains. Grow at $0-42{ }^{\circ} \mathrm{C}$. Predominant fatty acids are iso-15:1, iso-15:0, anteiso- $15: 0,15: 0$, iso- $16: 0$, summed feature 3 (comprising iso-15:0 2-OH and/or $16: 1 \omega 7 c$ ), iso-17:0 $3-\mathrm{OH}$ and $17: 02-\mathrm{OH}$. The major respiratory quinone is menaquinone- 6 . The DNA G $+\mathrm{C}$ content is $36.8-44.4 \mathrm{~mol} \%$. Known habitats are seawater and marine sediments, marine plants and invertebrates and hypersaline lakes. The type species is Salegentibacter salegens.

\section{Description of Salegentibacter catena sp. nov.}

Salegentibacter catena (ca.te' na. L. n. catena chain, referring to the fact that cells frequently occur in chains).

Cells are Gram-negative rods, $0.5-0.8 \times 2-6 \mu \mathrm{m}$, frequently occurring in chains and producing appendages in older cultures. Strictly aerobic. Devoid of flagellar and gliding motilities. Catalase-positive and oxidase-negative. Colonies on marine agar 2216 are saffron yellow, slimy, circular, convex and shiny, $3-5 \mathrm{~mm}$ in diameter after 5 days of incubation at $30^{\circ} \mathrm{C}$. Growth occurs at $15-42{ }^{\circ} \mathrm{C}$ (optimum, $33^{\circ} \mathrm{C}$ ), at pH 6.5-9.0 (optimum, 7.5-8.2) and in 0.1-10\% $\mathrm{NaCl}$ (optimum, 1-4\%). Arginine dihydrolase, urease and lecithinase are negative. $\mathrm{H}_{2} \mathrm{~S}$ is produced, but indole is not. Nitrate is not reduced. Aesculin, casein, gelatin, starch and Tween 20 are hydrolysed, but agar, DNA and carboxymethylcellulose are not. Weak growth and acid formation occur with glucose, but not with sucrose, mannose, maltose, arabinose, lactose, rhamnose, melibiose, fucose, raffinose, xylose, adonitol, inositol, sorbitol, gluconate, malonate, galactose, malate, citrate, pyruvate, lactate, propionate, acetate, alanine or proline. In API ZYM kits, activities of alkaline and acid phosphatases, esterase lipase (C8), leucine and valine arylamidases, naphthol-AS-BI-phosphohydrolase and $\alpha$-glucosidase are strong and activities of esterase (C4), lipase (C14), cystine arylamidase and trypsin are weak. Negative for activities of $\alpha$-chymotrypsin, $\beta$ galactosidase, $\beta$-glucosidase, $\beta$-glucuronidase, $\alpha$-fucosidase, $\alpha$-galactosidase, $\alpha$-mannosidase and $N$-acetyl $-\beta$-glucosaminidase. Resistant to gentamicin $(10 \mu \mathrm{g})$, neomycin $(30 \mu \mathrm{g})$, polymyxin $\mathrm{B}(300 \mu \mathrm{g})$ and streptomycin $(10 \mu \mathrm{g})$, but sensitive to ampicillin $(10 \mu \mathrm{g})$, carbenicillin $(100 \mu \mathrm{g})$, tetracycline $(30 \mu \mathrm{g})$, vancomycin $(30 \mu \mathrm{g})$, ciprofloxacin $(5 \mu \mathrm{g})$, rifampicin $(5 \mu \mathrm{g})$, norfloxacin $(10 \mu \mathrm{g})$, chloramphenicol $(30 \mu \mathrm{g})$, benzylpenicillin $(10 \mu \mathrm{g})$, kanamycin $(30 \mu \mathrm{g})$ and erythromycin $(15 \mu \mathrm{g})$. Cellular fatty acids ( $>1 \%$ of the total fatty acids) are iso-14:0 $(2.0 \%)$, iso$15: 1$ (5.0\%), anteiso-15:1 (1.3\%), iso-15:0 (6.8\%), anteiso-15:0 (6.4\%), 15: $1 \omega 6 c(2.6 \%), 15: 0$ (10.4\%), iso-16: $1(2.8 \%)$, iso-16:0 (13.5\%), summed feature 3 (comprising iso-15:0 2-OH and/or $16: 1 \omega 7 c ; 6.3 \%$ ), 16:0 $(4.3 \%)$, iso- $15: 03-\mathrm{OH}(1.2 \%), 15: 02-\mathrm{OH}(1.8 \%)$, iso$17: 1 \omega 9 c \quad(2.3 \%)$, anteiso- $17: 1 \omega 9 c \quad(2.3 \%), \quad 17: 1 \omega 8 c$ $(1.5 \%), \quad 17: 1 \omega 6 c \quad(2.4 \%), \quad$ iso- $16: 0 \quad 3-\mathrm{OH} \quad(3.6 \%)$, $18: 1 \omega 7 c(1.3 \%), 18: 0(2.6 \%)$, iso- $17: 03-\mathrm{OH}(5.2 \%)$ and $17: 02-\mathrm{OH}(5.0 \%)$. 
The $\mathrm{G}+\mathrm{C}$ content of the DNA of the type strain is $44.4 \mathrm{~mol} \%$. The type strain is $\mathrm{HY}^{\mathrm{T}}$ (=CGMCC $1.6101^{\mathrm{T}}=\mathrm{JCM} 14015^{\mathrm{T}}$ ), which was isolated from sediment of Xijiang oilfield in the South China Sea.

\section{Acknowledgements}

This work was supported by projects from the Chinese National Natural Science Foundation (30230010).

\section{References}

Bernardet, J.-F., Nakagawa, Y. \& Holmes, B. (2002). Proposed minimal standards for describing new taxa of the family Flavobacteriaceae and emended description of the family. Int J Syst Evol Microbiol 52, 1049-1070.

Bowman, J. P. \& McCuaig, R. D. (2003). Biodiversity, community structural shifts, and biogeography of prokaryotes within Antarctic continental shelf sediment. Appl Environ Microbiol 69, 2463-2483.

Bowman, J. P. \& Nichols, D. S. (2005). Novel members of the family Flavobacteriaceae from Antarctic maritime habitats including Subsaximicrobium wynnwilliamsii gen. nov., sp. nov., Subsaximicrobium saxinquilinus sp. nov., Subsaxibacter broadyi gen. nov., sp. nov., Lacinutrix copepodicola gen. nov., sp. nov., and novel species of the genera Bizionia, Gelidibacter and Gillisia. Int J Syst Evol Microbiol 55, 1471-1486.

Cho, J.-C. \& Giovannoni, S. J. (2003). Parvularcula bermudensis gen. nov., sp. nov., a marine bacterium that forms a deep branch in the $\alpha$ Proteobacteria. Int J Syst Evol Microbiol 53, 1031-1036.

Collins, M. D. (1985). Isoprenoid quinone analysis in classification and identification. In Chemical Methods in Bacterial Systematics, pp. 267-287. Edited by M. Goodfellow \& D. E. Minnikin. London: Academic Press.

Dobson, S. J., Colwell, R. R., McMeekin, T. A. \& Franzmann, P. D. (1993). Direct sequencing of the polymerase chain reaction-amplified 16S rRNA gene of Flavobacterium gondwanense sp. nov. and Flavobacterium salegens sp. nov., two new species from a hypersaline Antarctic lake. Int J Syst Bacteriol 43, 77-83.

Ivanova, E. P., Alexeeva, Y. V., Flavier, S., Wright, J. P., Zhukova, N. V., Gorshkova, N. M., Mikhailov, V. V., Nicolau, D. V. \& Christen, R. (2004). Formosa algae gen. nov., sp. nov., a novel member of the family Flavobacteriaceae. Int J Syst Evol Microbiol 54, 705-711.
Ivanova, E. P., Bowman, J. P., Christen, R., Zhukova, N. V., Lysenko, A. M., Gorshkova, N. M., Mitik-Dineva, N., Sergeev, A. F. \& Mikhailov, V. V. (2006). Salegentibacter flavus sp. nov. Int J Syst Evol Microbiol 56, 583-586.

Kumar, S., Tamura, K. \& Nei, M. (2004). MEGA3: integrated software for Molecular Evolutionary Genetics Analysis and sequence alignment. Brief Bioinform 5, 150-163.

Lane, D. J. (1991). 16S/23S rRNA sequencing. In Nucleic Acid Techniques in Bacterial Systematics, pp. 115-175. Edited by E. Stackebrandt \& M. Goodfellow. Chichester: Wiley.

Mandel, M. \& Marmur, J. (1968). Use of ultraviolet absorbance temperature profile for determining the guanine plus cytosine content of DNA. Methods Enzymol 12, 195-206.

McCammon, S. A. \& Bowman, J. P. (2000). Taxonomy of Antarctic Flavobacterium species: description of Flavobacterium gillisiae sp. nov., Flavobacterium tegetincola sp. nov. and Flavobacterium xanthum sp. nov., nom. rev. and reclassification of [Flavobacterium] salegens as Salegentibacter salegens gen. nov., comb. nov. Int J Syst Evol Microbiol 50, 1055-1063.

Nedashkovskaya, O. I., Suzuki, M., Vancanneyt, M., Cleenwerck, I., Zhukova, N. V., Vysotskii, M. V., Mikhailov, V. V. \& Swings, J. (2004). Salegentibacter holothuriorum sp. nov., isolated from the edible holothurian Apostichopus japonicus. Int J Syst Evol Microbiol 54, 1107-1110

Nedashkovskaya, O. I., Kim, S. B., Lysenko, A. M., Mikhailov, V. V., Bae, K. S. \& Kim, I. S. (2005). Salegentibacter mishustinae sp. nov., isolated from the sea urchin Strongylocentrotus intermedius. Int J Syst Evol Microbiol 55, 235-238.

Nedashkovskaya, O. I., Kim, S. B., Vancanneyt, M., Shin, D. S., Lysenko, A. M., Shevchenko, L. S., Krasokhin, V. B., Mikhailov, V. V., Swings, J. \& Bae, K. S. (2006). Salegentibacter agarivorans sp. nov., a novel marine bacterium of the family Flavobacteriaceae isolated from the sponge Artemisina sp. Int J Syst Evol Microbiol 56, 883-887.

Seidler, R. J. \& Mandel, M. (1971). Quantitative aspects of deoxyribonucleic acid renaturation: base composition, state of chromosome replication, and polynucleotide homologies. J Bacteriol 106, 608-614.

Van Trappen, S., Vandecandelaere, I., Mergaert, J. \& Swings, J. (2004). Gillisia limnaea gen. nov., sp. nov., a new member of the family Flavobacteriaceae isolated from a microbial mat in Lake Fryxell, Antarctica. Int J Syst Evol Microbiol 54, 445-448.

Wu, C., Lu, X., Qin, M., Wang, Y. \& Ruan, J. (1989). Analysis of menaquinone compound in microbial cells by HPLC. Microbiology (English translation of Mikrobiologiia) 16, 176-178. 